\title{
Patrimonio cultural e historiografía El caso de la Plaza de la Fundación en San Miguel de Tucumán
}

\author{
Cultural Heritage and Historiography \\ The Case of the Foundation Square in San Miguel de Tucumán
}

\author{
Ariel Ignacio Slavutsky \\ slavbell@gmail.com \\ Universidad Nacional de Jujuy / \\ Universidad Nacional de Tucumán. \\ Argentina
}

Recibido: $24 / 10 / 2019$

Aceptado: 18/3/2020

\begin{abstract}
Resumen
Desde su creación, la Argentina como Estado nación ha dedicado una parte importante de sus recursos culturales a la creación de una identidad social homogénea que permitiera a sus ciudadanos reconocerse como argentinos. Todos aquellos que quedaron fuera del proceso de homogeneización debían ser incluidos de alguna manera. En este trabajo analizaremos la forma en la cual se introdujeron a los pueblos originarios en la historia nacional a partir del estudio de la activación patrimonial de la plaza de la fundación en San Miguel de Tucumán. Nos interesa mostrar el entrecruzamiento de los discursos disciplinares y el patrimonio cultural y su transformación a lo largo del tiempo.
\end{abstract}

\section{Palabras clave}

Patrimonio cultural; historiografía; pueblos originarios; San Miguel de Tucumán

\begin{abstract}
Since its creation, Argentina as a nation-state has devoted an important part of its cultural resources to the creation of a homogeneous social identity that would allow its citizens to recognize themselves as Argentinian. All those who were left out of the process of homogenization had to be included in some way. In this work we will analyze how the original peoples were introduced into national history from the study of the heritage activation of the foundation square in San Miguel de Tucumán. We are interested in showing the interbreeding of disciplinary discourses and cultural heritage and their transformation over time.
\end{abstract}

\section{Keywords}

Cultural heritage; historiography; native peoples; San Miguel de Tucumán 
Desde su origen, la Argentina como Estado Nación ha dedicado, al igual que la mayoría de los Estados, una parte importante de sus recursos culturales a la creación de una identidad social homogénea que permita a sus ciudadanos reconocerse como argentinos. Esta búsqueda se logró por dos medios: uno afirmativo y otro negativo. El afirmativo consistió en la creación de instituciones educativas y culturales que posibilitaran a los sujetos adquirir elementos culturales pretendidamente objetivos, como el lenguaje, las formas de medir el espacio y la historia nacional. A lo cual se deben sumar todos los símbolos que constituyen la liturgia nacionalista, como el himno y la bandera (además del ejército, el correo, la escuela, la legislación). Por otro lado, el negativo se llevó a cabo en dos direcciones y, con un objetivo. El primer sentido fue hacia el exterior, diferenciándose de los países vecinos tanto por medio de la guerra y de la diplomacia, a la hora de establecer límites territoriales de los Estados, como a partir de la estereotipación de los países limítrofes, al momento de construir una comunidad imaginada (Anderson, 1993). La segunda dirección fue hacia el interior, ya que se produjo un acto afirmativo que legitimaba una forma de organizar y de narrar la historia nacional que implicaba la negación simbólica de las otras identificaciones que no se encontraran incluidas en el estereotipo del ideal nacional.

Sin embargo, el relato no podía ser incompleto: si efectivamente debíamos contar la historia nacional desde sus simientes, los pueblos originarios debían estar presentes. La idea moderna de progreso indefinido sirvió de marco teórico que permitió la introducción de estos otros como elementos del pasado de un país bárbaro que se encaminaba a la civilización gracias a las dotes de la modernidad. Facundo o Civilización y Barbarie (1845), de Domingo Faustino Sarmiento, da cuenta de este espíritu civilizatorio.

Esta visión de los vencedores dejó impresas infinidad de imágenes que se hicieron y se hacen presentes en la vida cotidiana de todos los argentinos, en las calles, en los museos, en los sitios arqueológicos; los pueblos originarios son representados una y otra vez. Estas imágenes son acompañadas por discursos públicos legitimadoslegitimadores, entre los que se encuentra el discurso académico, que cumple, en muchas ocasiones, funciones pedagógicas. Es decir, enseñan cómo deben ser leídas e interpretadas estas presencias.

En ocasiones, las imágenes toman la forma de esculturas, fruto de la imaginación artística de un sujeto, y pasan a formar parte de nuestros recorridos cotidianos. Muchas de estas han sido testigos 


\section{ARTICULOS}

de las transformaciones ideológicas de los aparatos del Estado y de sus proyectos identitarios, económicos y sociales, desde una versión triunfalista liberal, occidental y católica, donde predominó el mito de la nación blanca y el crisol de razas, hasta el multiculturalismo de la década de 1990 donde los pueblos originarios fueron valorados positivamente -aunque eso no implicase una mejora sustancial en su situación-.

En este artículo proponemos analizar el caso de un espacio público denominado Plaza de la Fundación, ubicado en el Parque Avellaneda de la ciudad de San Miguel de Tucumán. Consta de una escultura central del fundador de la ciudad, Diego de Villarroel, de dos paneles con la imagen de los pueblos originarios rindiéndose ante el poder de la cruz y de una serie de cartelería que recorre la historia de la provincia; al frente, se encuentra el monumento al Bicentenario de la Declaración de Independencia; detrás, el Parque Avellaneda y, al oeste, el cementerio.

Para analizar el proceso de transformación nos parecen útiles los conceptos de espacio social y de patrimonio cultural, que nos permitirán dar cuenta no solo de la construcción social del espacio, sino también de un proceso de construcción discursiva y cultural que se propone generar y fortalecer una identidad nacional y local. Entendemos por patrimonio cultural a una síntesis simbólica que se propone representar una construcción identitaria hegemónica (Prats, 2004). Estos bienes culturales pueden ser el resultado de un proceso de apropiación de objetos tales como yacimientos arqueológicos. Pero también existen elementos realizados a pedido para la representación de un prócer o de un hecho histórico previamente interpretado por el mecenas, que requiere del artista para la producción de una obra que pueda ser ubicada dentro del discurso y de la interpretación del pasado afín a sus intereses.

Ahora bien, suele identificarse la activación patrimonial con dos ideas: por un lado, la puesta en valor de los bienes culturales; por el otro, su conservación y estudio. Ambas dan una imagen del patrimonio cultural a partir de elementos que se encuentran detenidos en el tiempo, sin variantes. Sin embargo, esto rara vez es asíy, auncuando esto fuera posible, siempre habrátransformaciones en su contexto y en su interpretación. Esta situación se evidencia con mayor fuerza en el caso de los bienes culturales que forman parte del paisaje urbano, donde la transformación de su entorno responde al dinamismo propio de las ciudades. 
1 No hemos estudiado los festejos previos a esta fecha, pero por las prácticas posteriores podemos suponer que consistían en una visita al sitio original de la ciudad, en el paraje de Ibatín, departamento de Monteros.
La Historia como discurso legitimado y legitimador se refleja en las activaciones patrimoniales a través de los profesionales que ven en estas ocasiones la oportunidad de acrecentar su capital académico y social (Bourdieu, 2008). Estos discursos siguen los derroteros locales de la disciplina. En el caso que estudiamos, los agentes que participan ocupan posiciones institucionales importantes dentro de la construcción de la disciplina, por lo que no parece casual su participación en estos actos públicos.

\section{El proceso de construcción de la Plaza de la Fundación}

En 1935, el gobierno de la ciudad de San Miguel de Tucumán decidió realizar una intervención artística que rememorara el hecho histórico, ${ }^{1}$ así fue que se llevó a cabo un concurso para la ejecución de una escultura de Diego de Villarroel. Al mismo se presentaron Ángel Dato, Enrique Prat Gay y Juan Carlos Iramain. Este último fue el ganador.

La obra se inauguró el 28 de septiembre de 1936 durante la presidencia de Roberto Marcelino Ortiz y la gobernación de Miguel Mario Campero de la Unión Cívica Radical Concurrencista, una rama del partido que se formó con la intención de participar en las elecciones desobedeciendo la estrategia abstencionista de la dirección nacional del partido; también el intendente de la ciudad pertenecía a una rama del radicalismo.

La efigie se ubicó en la platabanda de la avenida Mate de Luna, una de las calles principales de la ciudad, lo cual le dio un lugar preponderante en la configuración del espacio público del paisaje urbano. En esta primera etapa de la Plaza de la Fundación, se produce una borradura «institucional y muy material» (Loraux, 1989, p. 32). En efecto, ni la imagen de Villarroel ni los discursos en torno a él daban cuenta del rol de los pueblos originarios en la fundación de la ciudad. San Miguel de Tucumán fue pensada, originalmente, para la contención de los pueblos indios, estableciendo un nuevo punto de avanzada allí donde ya habían sido destruidas otras ciudades.

El discurso del doctor Manuel Lizondo Borda, quien ocupó un lugar preponderante en la creación y en el desarrollo de la disciplina histórica en la provincia, se encuentra acorde a la imagen: 


\begin{abstract}
Descendientes de esos conquistadores y primitivos pobladores fueron la mayor parte de los criollos que lucharon por nuestra nacionalidad. Y estos nunca pudieron renegar de aquellos. Ellos quisieron romper el lazo exterior que los ataba a España y guerrearon contra «los peninsulares» - $y$ secuaces- que la representaban. Nada más. Y eso era lo natural y lógico.

De suerte que estos «peninsulares» que inundaron el suelo de argentina a fines del siglo XVIII y que vinieron nada más que a gozar de los beneficios coloniales, sólo esos "peninsulares» pudieron llamarse nuestros enemigos. Pero nunca, los conquistadores, los primitivos pobladores y los primeros criollos que con su trabajo y con sus sacrificios echaron los cimientos de nuestras ciudades, las habitaron, labraron nuestras tierras, formaron aquí sus familias y aquí dejaron sus huesos y su descendencia. Porque ellos son nuestros antepasados, los forjadores de nuestros orígenes y por eso la parte fundamental de nuestra historia (Fue inaugurado el ayer el monumento a Villarroel, 1936, p. 7).
\end{abstract}

El pasado con el que se pretende conectar es claro, no es con el de los pueblos originarios, que no se encuentran ni siquiera representados en el discurso, ni con el de los Peninsulares llegados durante el período borbón. Somos descendientes de los conquistadores y de nadie más. Incluso el futuro director de la Junta y del archivo histórico de la provincia aprobó la ubicación urbana que une la primera y la segunda fundación de la ciudad.

Está bien así mismo que este monumento a Villarroel se alce en la vieja Avenida de árboles enhiestos, que lleva el nombre de Mate de Luna. Porque, así, al recuerdo de la traslación de esta ciudad se unirá la memoria de la fundación y la existencia de la primitiva San Miguel de Tucumán. Y porque así nuestro pueblo empezará a conocer, y con ello se interesará por conocer mejor, que no somos tan de ayer, ni tan faltos de tradición como se cree; que antes de estar aquí, nuestros antepasados vivieron 120 años allá en Ibatin, 120 años plenamente vividos, llenos de vicisitudes y de hechos memorables, y que esta ciudad nueva tampoco es reciente, pues tiene ya 251 años cumplidos, igualmente ricos de historia colonial (Fue inaugurado el ayer el monumento a Villarroel, 1936, p. 7).

Podemos observar cómo la creación artística de Iramain posee todas las características de su época, ya que logra, en una suerte de archivo foucaultiano, ordenar todos los elementos del período en una síntesis que cobra fuerza a partir de la confluencia de múltiples discursos y prácticas que se articulan de forma laxa, aunque exacta, sin un director de orquesta, aunque ordenadas. 
En 1944, la efigie se traslada de la platabanda a la vereda del actual Parque Avellaneda donde aún se encuentra. Es en el año 1965 cuando se produce una transformación importante en el contexto en el cual se encuentra emplazada la estatua: a la figura de Villarroel se le agregan dos paneles creados a pedido de la Municipalidad por Ángel Dato y Roberto Fernández Larrinaga. En este cuarto centenario, las festividades tuvieron una importancia aún mayor a la dada en las intervenciones anteriores.

Estos nuevos paneles introducen la figura del indio, que también aparece en el discurso gráfico, nuevamente de la mano de un historiador que se desempeñó como docente de la Universidad Nacional de Tucumán en la carrera de Historia, en las cátedras de Historia de América I y II (períodos colonial e independiente). Así se expresaba el profesor Rodolfo Cerviño (1965):

La Historia de los pueblos hispanoamericanos no empieza con el advenimiento a la vida independiente. Es con la llegada de los españoles a las playas de América cuando se les ofrece «a las innumerables razas autóctonas, dispares e inconexas, el telar donde una y otra pudieron unir al fin sus hilos solitarios en una trama armónica y común».

La Historia de América se inicia como cruzada. Nacimos no a una cultura cualquiera, sino a la precisa cultura de la cristiandad, identificados con el culto de la verdad del Evangelio. Y lo más grande, lo más caballeresco de España con relación a América se manifestó de entrada, con los problemas de conciencia que el trato a los naturales y el derecho de dominio sobre estas tierras suscitaron al encontrárselas habitadas. Todas las preguntas que cualquier nación colonizadora puede hacerse, pero que solo España se las hizo, fueron formuladas y respondidas. ¿Eran los indígenas seres racionales? ¿Eran una especie intermedia entre el hombre y las bestias? O bien, ¿del todo irracionales? ¿Qué títulos inobjetables podía exhibir el rey de España sobre el Nuevo Mundo? ¿En qué condiciones podía hacerse la «guerra justa» contra los indios? (p. 2).

El discurso del profesor Cerviño (1965) en parte concuerda con el del doctor Lizondo Borda cuando remite el origen de la identidad nacional, provincial e hispanoamericana a los conquistadores e hidalgos del siglo XVI y XVII. Pero además aparece aquí la idea clara de evangelizar y de civilizar a las razas autóctonas, que sin el aporte español se encontraban aisladas y que gracias a la colaboración de la cristiandad y de la cultura hispana pudieron unificarse. Incluso llega a expresar que los españoles se preocuparon de proteger a los pueblos 
originarios a través de las Leyes de Indias: «Hubo abusos; pero de parte de individuos que actuaron así por su cuenta y de espaldas a la ley, como en todos los países y en todos los tiempos ocurre. No el abuso generalizado de la Leyenda Negra» (Cerviño, 1965, p. 2).

La imagen de los paneles refleja esta idea del historiador tucumano. En los mismos es posible ver a los indios siendo protegidos y educados por la Iglesia y la conquista. El diario La Gaceta publicó el 31 de mayo de 1965 una imagen de un fotomontaje que sintetiza la idea de la época [Figura 1].

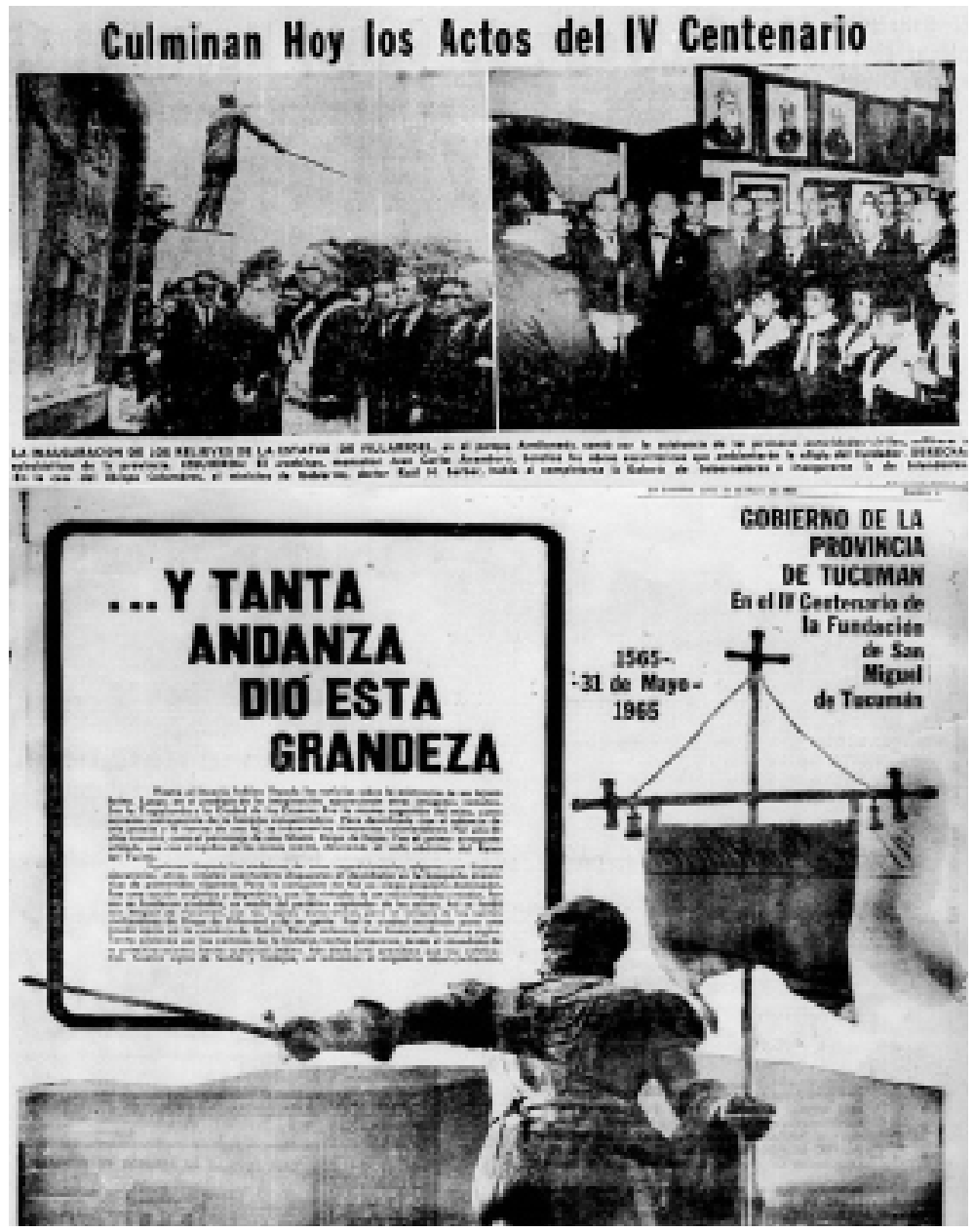

Figura 1. Fotos del diario La Gaceta del 31 de mayo de 1965. Arriba, acto de inauguración de los paneles. Abajo, fotomontaje alusivo 
En septiembre de 2013, después de cuarenta y ocho años, se decide realizar una nueva intervención, esta vez con una serie de arcos y de paneles que recorren toda la historia de la ciudad, pero con un discurso totalmente diferente que genera una contradicción entre lo que es posible observar en las imágenes y en la cartelera [Figura 2].

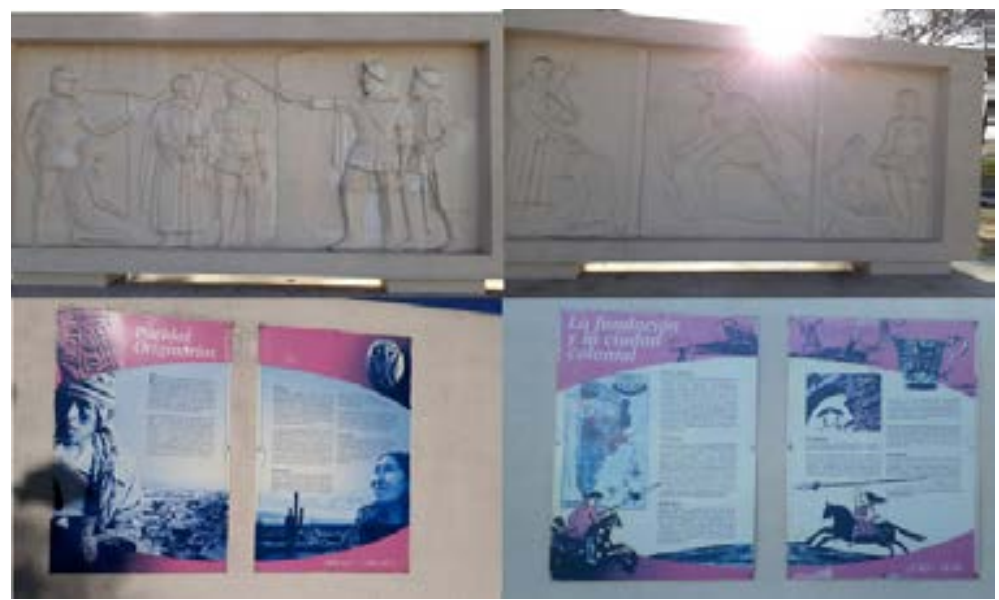

Figura 2. Foto del autor. Arriba, cara de los paneles inaugurados en 1965. Abajo, contracara de los paneles inaugurados en 2013

En la imagen de la contracara del panel izquierdo se ve un fotomontaje en el que se mezclan representaciones de personas con rasgos originarios, mientras que de fondo se observa la ciudad sagrada de Quilmes -uno de los yacimientos arqueológicos intervenido por el equipo del Instituto Interdisciplinario Tilcara de la Universidad Nacional de Buenos Aires con Norberto Pelissero y Horacio Difrieri a la cabeza-. El texto hace referencia al alcance del desarrollo cultural de los pueblos originarios antes de la llegada de los españoles, exaltando sus logros tecnológicos. Se genera aquí una suerte de oxímoron, ya que de un lado de los paneles se encuentra una oda a la conquista y a la evangelización y, del otro, una revalorización de los pueblos originarios.

Ese es el inicio de un recorrido en el que se pretende recuperar la historia de la ciudad desde su fundación hasta el año 2013, cuando fueron inauguradas las obras. El relato de los vaivenes de la ciudad se recorre a través de arcos rectangulares que van desde la escultura hasta el final de la plaza [Figura 3]. 


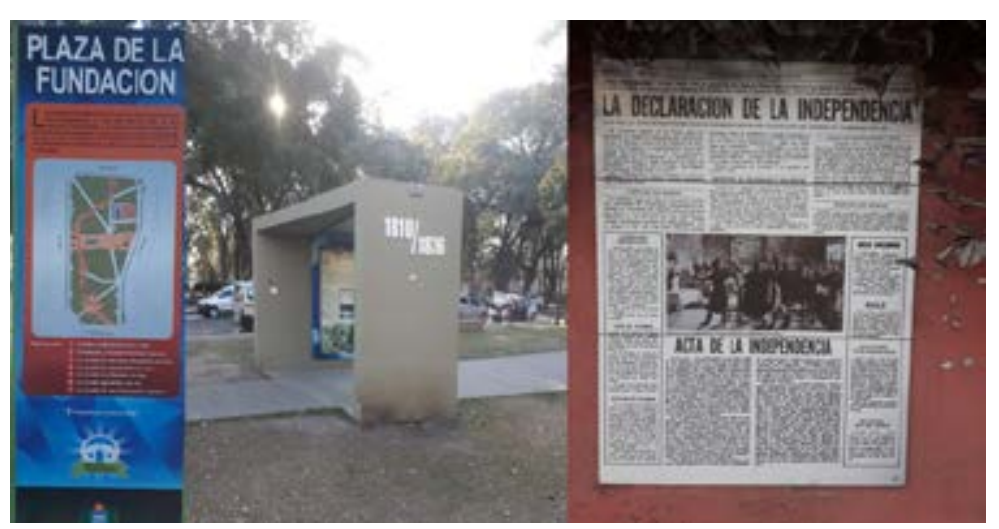

Figura 3. Foto del autor del recorrido histórico de la plaza y los cerámicos sobre calle Lucas Córdoba

El discurso histórico [Figura 3], enfrascado en vinilos en las paredes laterales de los rectángulos tiene un claro interés de divulgación, que mantiene algún tipo de relación con las reproducciones hechas en cerámicos del libro de Jorge Perrone, Diario de la historia Argentina (1974). Estas se emplazan en la pared lateral del Museo de la Universidad Nacional de Tucumán ubicado sobre la calle Lucas Córdoba entre calles San Martín y Mendoza, inmediatamente en diagonal a la Plaza de la Fundación y al frente del Cementerio del Oeste (considerado patrimonio cultural). Las cuarenta y cuatro imágenes se presentan con formato de un periódico que abarca la historia nacional, desde las Invasiones Inglesas hasta la Declaración de Independencia.

En el mismo espacio se creó, en 2016, sobre la misma platabanda donde originalmente se encontraba la estatua de Villarroel, el monumento al Bicentenario de la Declaración de la Independencia [Figura 4], lo cual generó una relación simbólica entre la fundación de la ciudad y de la república. En este último, no existe ninguna representación de los pueblos originarios, solo de la bandera nacional, que se ha transformado en las últimas festividades en el centro de atención simbólico dejando de lado el complejo de la Plaza de la Fundación. 


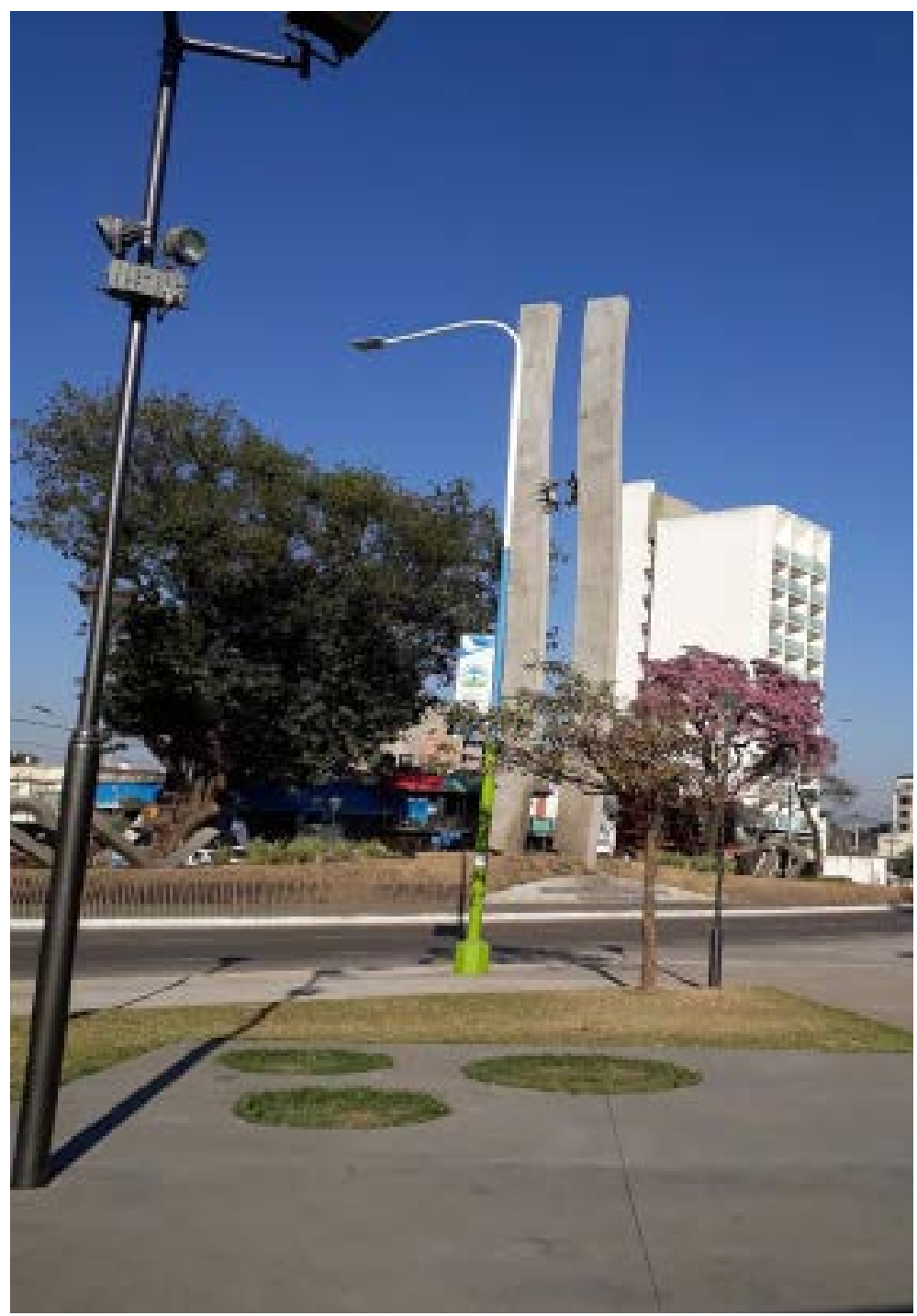

Figura 4. Foto del autor tomada desde la efigie de Villarroel

\section{Algunas reflexiones finales}

A lo largo de este recorrido histórico, hemos recuperado discursos e imágenes que dan cuenta del proceso de construcción de la identidad nacional. Es un proceso en continua reinterpretación, siempre a la saga de otredades que exceden los intentos de 
homogeneizar una población que se sabe múltiple y, sin embargo, lo intenta. La idea de una argentinidad o de una tucumanidad parece necesaria para la formación de un Estado, algo que incluya y nuclee alrededor de un territorio separado artificialmente, cuyos habitantes debieron ser inventados y reinventados con la finalidad de dar cohesión y justificación. La utilización de los aparatos ideológicos del Estado (Althusser, 1989) para intentar lograr la hegemonía posibilita una gran cuota de éxito en este sentido (Gramsci, 1981).

Esta particular configuración del espacio, donde confluyen nuevos y viejos discursos plasmados en imágenes y en palabras, no sería posible en un estado de conservación absoluta donde no existieran reinterpretaciones constantes de los bienes culturales. Estas reinterpretaciones se superponen como sedimentos que configuran un espacio complejo posible de deconstruir a partir de la recuperación sincrónica de sus capas. La resultante es una serie de fotografías. Ahora, cuando llegamos al final, el paisaje muestra la trayectoria elíptica, muchas veces contradictoria. Donde los discursos de la disciplina, la política, el arte y la tecnología se entrecruzan generando un espacio dinámico y continuamente reinterpretado y, por ende, reubicado e intervenido. Son discursos sobre lo nacional, lo provincial y lo local que solo pueden comprenderse si recuperamos sus recorridos.

Así visto, el patrimonio cultural, sea encerrado en una vitrina de un museo o en una plaza, es continuamente transformado en tanto su significado es dinámico, cambia a la luz de los proyectos culturales e identitarios hegemónicos, muy vinculados a las ideologías de los gobiernos de turno. Aquí la Historia como disciplina y los historiadores en su práctica tienen una función fundamental como portadores de un saber legitimado socialmente, aportan su capital simbólico para la legitimación de estas prácticas. En nuestro trabajo los vemos aparecer desde un comienzo en las palabras de distintas personas que ocuparon un papel importante en la construcción del espacio académico tucumano.

\section{Referencias}

Althusser, L. (1989). La Filosofía como arma de la revolución. Ciudad de México, México: Siglo Veintiuno. 
Anderson, B. (1993). Comunidades imaginadas: Reflexiones sobre el origen y la difusión del nacionalismo. Ciudad Autónoma de Buenos Aires, Argentina: Fondo de Cultura Económica.

Bourdieu, P. (2008). Los usos sociales de la ciencia. Ciudad Autónoma de Buenos Aires, Argentina: Editions Quae.

Cerviño, R. (31 de mayo de 1965). En torno a la conquista. La Gaceta, p. 2.

Fue inaugurada ayer el monumento a Villarroel. (28 de septiembre de 1936). La Gaceta, p. 7.

Gramsci, A. (1981). Cuadernos de la cárcel. Tomo 1. Ciudad de México, México: Ediciones Era.

Loraux, N. (1989). De la Amnistía y su contrario. En Y. Yerushalmi y otros, Usos del olvido (pp. 27-52). Ciudad Autónoma de Buenos Aires, Argentina: Nueva Visión.

Perrone, J. (1974). Diario de la historia argentina. Ciudad Autónoma de Buenos Aires, Argentina: Ediciones Latitud 34.

Prats, L. (2004). Antropología y Patrimonio. Barcelona, España: Ariel. 